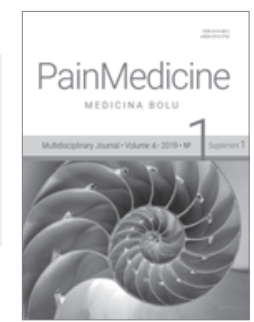

DOI: $10.31636 /$ pmjua.t2.15

\title{
Comparative characteristics of life quality in patients with distant consequences of combat brain injury
}

\author{
Chernenko Inna \\ Kharkov National medical university, Kharkiv, Ukraine
}

Objective: To define the main directions of diagnostic, therapeutic and rehabilitation actions in persons, who have had a combat brain injury on the basis of assessment and comparison of indicators of life quality in various terms of postponed trauma.

Material and methods: we have examined 180 males: 100 combatants in the Democratic republic of Afghanistan (19791989) and 80 combatants of the conflict in the East of Ukraine (from 2014 till present) with consequences of a combat brain injury of varying severity. We used clinical-neurological, instrumental (craniography of skull, magnetic resonance imaging, ultrasonic doppler sonography of the main vessels of the head and neck), biochemical, statistical methods of research, and also questionnaire scale SF-36.

Results: the study found that indicators of life quality in persons, who have had a combat brain injury depend on severity and term which has passed from the getting combat brain injury. In early terms after the combat brain injury and also in persons who have had minor and moderate degree combat brain injury, the indicators connected with a psychological component are mainly broken. While the patients, who have had a combat brain injury, have violations of all aspects (physical, psychological and social), which in the absence of necessary rehabilitation and treatment, identically shown in the different terms of trauma.

Conclusion: according to the results the level of life quality is in many respects caused by the degree of functional violations leading to activity restriction first of all in the social life, considerably affect adaptation potential of organism.

Keywords: combat brain injury, quality of life, diagnostics, SF-36. 